\title{
Effects of family income and conditional cash transfers on household food insecurity: evidence from a longitudinal study in Northeast Brazil
}

\author{
Poliana A Palmeira ${ }^{1,2, *}$, Rosana Salles-Costa ${ }^{1}$ and Rafael Pérez-Escamilla ${ }^{3}$ \\ ${ }^{1}$ Institute of Nutrition Josué de Castro, University of Rio de Janeiro, Carlos Chagas Filho Av. 367, bloco J - $2^{\circ}$ andar - \\ sala 18, Rio de Janeiro, RJ 21941-590, Brazil: ${ }^{2}$ Center of Education and Health, University of Campina Grande, \\ Cuité, PB, Brazil: ${ }^{3}$ Department of Social and Behavioral Sciences, Yale School of Public Health, New Haven, CT, USA
}

Submitted 26 July 2018: Final revision received 21 June 2019: Accepted 11 July 2019: First published online 5 November 2019

\begin{abstract}
Objective: Food insecurity (FI) is a challenge to policy makers worldwide, who need to understand which polices and programmes are effective at overcoming FI. The present study aimed to examine the impact of family income and conditional cash transfers on changes in household FI status in a highly vulnerable municipality in Northeast Brazil.

Design: A population-based longitudinal cohort study among families in a municipality in the semi-arid area in Northeast Brazil (2011 and 2014). FI was estimated with the Brazilian Household Food Insecurity Measurement Scale (EBIA). The effects of family income and cash transfer on changes in FI were estimated using logistic regression models and the population-attributable risk fraction.

Setting: Households in Cuité, Paraîba, Brazil.

Participants: Household respondents interviewed in 2011 ( $n$ 358) and 2014 (n 326).

Results: There was a reduction in FI prevalence of $17.5 \%$ across time; $24.5 \%$ of families who were food insecure in 2011 became food secure in 2014. After adjustment, families that did not experience an increase in their total household income or a reduction in the cash transfer amount were at increased risk of persistent FI across time. If the cash transfer programme had not been in place, about $10 \%$ of the families that switched from food insecure to food secure across time would have remained in FI instead.

Conclusions: The decrease of FI occurred in an area of extreme climatic and social vulnerability. These changes were more related to the cash transfer than the increase in family income over time.
\end{abstract}

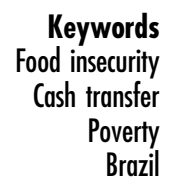

Food insecurity (FI) exists when there is deprivation or uncertainty about access to quality food in sufficient quantity, representing the violation of the human right to adequate food ${ }^{(1)}$. FI has also been identified as a risk factor for chronic diseases ${ }^{(2,3)}$ and poor mental health ${ }^{(4,5)}$, and it remains an important social and public health problem across countries with different levels of economic development ${ }^{(6-9)}$.

The FAO estimates that 700 million people suffer from severe FI or hunger worldwide. The latest report on the State of Food and Nutrition Security in the World indicates that, after a long period of decline, FI rates have increased, especially among countries in Latin America and subSaharan Africa ${ }^{(10)}$.
The FI status of a population is influenced by changes in macroeconomic, political and climatic factors ${ }^{(11)}$. Among the main limiting factors for household access to food are poverty and social inequalities; indeed, the inverse relationship between family income and FI level has been previously documented ${ }^{(12,13)}$. Recently, researchers have suggested that it is important to take into account all sources of family income, including cash transfers from social protection programmes, when examining the relationship between FI and family income ${ }^{(14,15)}$. This approach is needed to develop better social policies seeking to mitigate the risk of FI.

Studies have examined the effects of cash transfer programmes on $\mathrm{FI}^{(16)}$. Research conducted in Europe has 
identified that, during the economic recession, families were protected from FI if there was sufficient government spending on social protection programmes ${ }^{(17)}$. In Canada, one study found that access to social protection benefits helped decrease FI prevalence, but it was not enough to protect families against FI in periods of economic recession ${ }^{(18)}$. Another study in Canada pointed out a decrease in FI over time among families receiving cash transfers ${ }^{(19)}$. In sub-Saharan Africa, cash transfer programmes implemented in Ethiopia, Malawi and Kenya showed a positive impact on household dietary variety, but no effects were identified in Lesotho and Zambia $^{(20)}$.

The results of these studies are inconclusive and controversial. Furthermore, studies have used different instruments to capture FI, some of which have not been properly validated. Most studies have not used FI experience-based scales, which is unfortunate as these have been well validated globally ${ }^{(21,22)}$. Furthermore, most studies have been cross-sectional, indicating the need for cohort studies to find out whether changes in household income over time relate to household FI or not.

The objectives of the present study were to: (i) examine prospectively the change in FI among families living in a socio-economically deprived Brazilian municipality between 2011 and 2014; and (ii) analyse if changes in household income and the cash transfer amount received through a governmental programme were associated with FI change.

\section{Methods}

\section{Sample}

A population-based longitudinal cohort study was conducted in the Brazilian municipality of Cuité, located in the state of Paraíba, $235 \mathrm{~km}$ from the state capital, in the semi-arid Northeast area. The municipality is divided into rural and urban areas, has approximately 20000 inhabitants and a low human development index $(0.591)^{(23)}$. Baseline data were collected in 2011 through a representative cross-sectional survey of urban and rural populations of this municipality. The sample size was calculated using the stratified random sampling technique, dividing the municipality into an urban and rural region, proportionally. A maximum sampling error of $5 \%$ was used with a $95 \%$ CI. Based on an expected prevalence of FI of $50 \%{ }^{(24)}$ and the number of households in Cuité (5869 households) ${ }^{(25)}$, the estimated sample size was 360 households. In order to maintain the proportion of households from urban and rural areas in Cuité, we distributed the sample proportionally ending up with 243 (67.5\%) and 117 (32.5\%) households from urban and rural areas, respectively (Fig. 1).

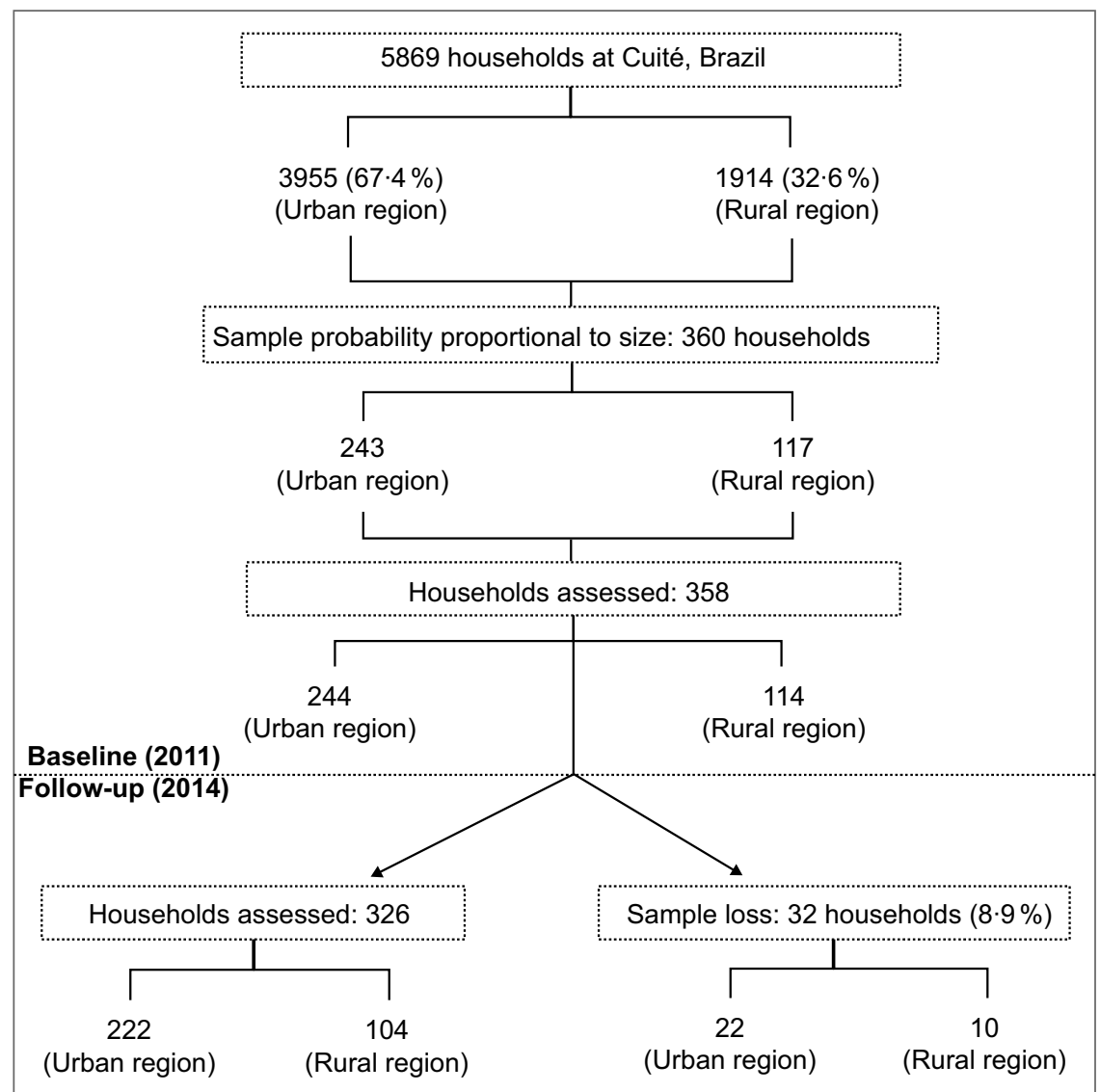

Fig. 1 Flowchart describing the baseline sampling and follow-up; Cuité, Paraíba, Brazil, 2011-2014 
The households surveyed were randomly selected; in the urban area based on the municipality register of urban houses, and in the rural area based on randomly selected coordinates on the municipality's map. Data were collected between May and June 2011 (358 households). The followup happened between May and September 2014, when 326 households were surveyed again, resulting in a sample loss of $8.9 \%$ (Fig. 1) and a sampling error of 0.054 . The sample attrition was mainly due to families moving to other regions of Brazil. The questionnaires were administered at home by twelve trained undergraduate students in 2011 and by twenty-three trained undergraduate students in 2014.

\section{Outcome variable}

The outcome of interest in the present study was FI measured with the Brazilian Household Food Insecurity Measurement Scale (Escala Brasileira de Insegurança Alimentar, EBIA). EBIA is an experience-based scale adapted from the US Household Food Security Survey Module, that has been validated for use in Brazil since $2003^{(26)}$. The theoretical underpinning of this instrument considers FI to be a progressive phenomenon experienced at the household level with different levels of severity. EBIA assesses four levels of food security/FI, representing worry of suffering from food deprivation, reduction of quality and/or amount of food accessed by the family and hunger. EBIA has consistently been shown to be psychometrically valid $^{(27-29)}$, reinforcing its suitability in monitoring FI through prevalence studies, identifying at-risk populations and studying the causes (e.g. poverty) and consequences (e.g. dietary and health outcomes) of $\mathrm{FI}^{(30)}$.

We used the fourteen-item EBIA version to capture household FI during the 3 months preceding the interview $^{(27,31)}$. The scale consisted of fourteen dichotomous (yes or no) items for households with children and/or adolescents under 18 years of age, and seven items for households where only adults lived. Based on the sum of affirmative responses to EBIA items and household composition (with or without children and adolescents under 18 years), households were classified in four categories of food security/FI: (i) 'food security (FS)' (score $=0$ ); (ii) 'mild' FI (score $=1-5$ in households with children/ adolescents, 1-3 in adult-only households); (iii) 'moderate' FI (score $=6-9$ in households with children/adolescents, 4-5 in adult-only households); and (iv) 'severe' FI (score $=10-14$ in households with children/adolescents, 6-8 in adult-only households) ${ }^{(32)}$.

For the analyses examining change in FI across time, the FI variable was categorized as: (i) FS at both visits, i.e. household classified as FS at baseline and follow-up (reference category); (ii) FI at both visits, i.e. household classified with some level of FI at baseline and follow-up; (iii) changed to FS, i.e. household classified at some level of FI at baseline with improvement to FS at follow-up; and (iv) changed to FI, i.e. household classified as FS at baseline and became FI at follow-up.

\section{Predictor variables}

Household income and cash transfer amount from social programmes were the independent variables predicting the change in FI across time. Income from work, pension or retirement of each household member was reported by the interviewee. The household income was examined considering the household total and per capita value at each period of the study, and the average comparing baseline and follow-up. The monthly per capita household income was further categorized as minimum wage multiples (up to $1 / 4$; above $1 / 4$ to $1 / 2$ minimum wage; above $1 / 2$ to 1 minimum wage; above 1 minimum wage). The Brazilian minimum wages were $\$$ US $340 \cdot 6$ ( $\$$ \$ 545; where $\mathrm{R} \$$ is Brazilian real) in 2011 and \$US 329.1 ( $\mathrm{R} \$ 724$ ) in 2014; the corresponding US dollar-real exchange average rates were $R \$ 1.6$ and $R \$ 2.2$ per US dollar, respectively.

The total household income at baseline and follow-up was categorized longitudinally into three groups: (i) increased by more than $1 / 2$ minimum wage when comparing follow-up and baseline; (ii) increased by up to $1 / 2$ minimum wage from baseline; and (iii) same or less at endline than baseline.

Regarding the cash transfer from social programmes, the programme involved was Bolsa Familia (PBF), launched in 2003. The PBF eligibility criterion is determined by poverty level based on monthly per capita family income. During both study periods, the poverty line in Brazil was defined as a per capita family income of up to \$US 87.5 (R\$140) in 2011 and \$US 70 (R\$154) in 2014. The cash transfer amount from PBF was composed of a fixed amount (2011: \$US 43.8 (R \$ 70); 2014: \$US 35 ( $\mathrm{R} \$ 77)$ ) plus a variable amount according to family composition (number of children, adolescents and pregnant women). Since 2012, the value of the cash transfer was also determined by the poverty gap. If the sum of a family's income and the benefits they already receive did not reach $\$$ US 35 ( $R \$ 77$ ), the family received an additional benefit amount required to reach this minimal household income ${ }^{(33,34)}$. The cash transfer amount from the PBF was informed by the interviewee.

The total cash transfer received by the household and how it changed between baseline and follow-up were analysed considering: (i) non-beneficiary at both visits, i.e. family not benefited by PBF at baseline and at follow-up; (ii) same or more cash transfer at endline than baseline, which included new beneficiaries of the programme; and (iii) lesser cash transfer at endline than baseline, i.e. households that received at follow-up an amount lower than that reported at baseline, which included families that left the programme. We also evaluated household income dependency on PBF by estimating the percentage of the total household income coming from the cash transfer. The change in family income dependency from PBF was 
compared between baseline and follow-up using the following three categories: (i) non-dependent at both visits; (ii) same or more dependent at endline than baseline; and (iii) less dependent at endline than baseline.

\section{Statistical analyses}

Descriptive household socio-economic data were estimated according to levels of FI and the dynamics of the change in FI status at different levels of severity across time.

To describe the probabilities of FI according to household income and cash transfer amount from PBF, logistic regression models were developed for each predictor variable at both study time points (baseline and follow-up). Mean probabilities of FI were estimated across per capita household income brackets and cash transfer amounts from PBF.

Multiple logistic regression with robust standard errors adjustments for key confounders was used to analyse the association between the predictor variables (i.e. household income, cash transfer amount and percentage of income dependency from cash transfer) and the outcome (i.e. change in FI between follow-up and baseline). First, a univariate analysis between each predictor variable and the outcome was performed. Next, we estimated separately a multiple logistic regression for each predictor variable, and lastly, we estimated a model for household income and cash transfer amount, simultaneously.

To estimate how much reduction in FI could be expected if all households did not receive any cash transfer over time we computed the population-attributable risk fraction (PAR; Stata command: punaf) from the model that included change in household income, cash transfer amount and confounders that the model adjusted for ${ }^{(35)}$. PAR estimates the impact of exposure comparing prevalence of the outcome in both scenarios, the observed sample scenario and the scenario in which the PBF was not implemented. We also estimated the predicted probabilities for 'change to FS' category according to the average family income between baseline and follow-up.

Only twenty-seven households were classified in the category 'changed to FI'. Due to lack of statistical power, the multinomial regression data for this group of households are not reported.

The confounders included in the adjusted models were: (i) region of residence; (ii) household food production for self-consumption; (iii) family living in own home; (iv) access to food assistance programmes; and (v) access to emergency cash benefits. In the period of the study, two food assistance programmes were implemented: Food Basket (distribution of basic food baskets) and Leite da Paraíba programme (distribution of one litre of milk daily to low-income families with children younger than 7 years of age and/or pregnant women). Additionally, an emergency cash transfer programme, Safra Guarantee, was offered to small-scale farmers who lost their crops due to drought or heavy rain. Logistic regression models were also adjusted for the number of household members to control for household size on the effect of predictor variables on FI. The variables total household income and cash transfer amount from PBF at baseline were included in the models that evaluated follow-up data and longitudinal variables, to adjust the analyses for the socio-economic condition of each household at the beginning of the study. All models were tested for collinearity using variance inflation factors; the variables included in the model had an average variance inflation factor of $<4^{(36)}$. All analyses were performed with Stata/IC $15 \cdot 0^{(37)}$.

\section{Results}

\section{Sample characteristics}

At baseline, $44.4 \%$ of households were FS, $31.0 \%$ experienced mild FI, $12.8 \%$ experienced moderate FI and $11.7 \%$ experienced severe FI, highlighting the social vulnerability of the households studied. FI was more prevalent and severe among households with lower per capita income, beneficiaries from PBF and households with more dependency on the cash transfer from this programme. The following were risk factors for FI: living in the rural region, not owning their own home, producing food for self-consumption, participating in emergency cash benefit programmes and not having retirees living in the household (Table 1).

No significant differences were found for FI, household income and participation in $\mathrm{PBF}$ when comparing households that completed the study with those lost at follow-up (data not shown).

\section{Changes in food insecurity}

The overall prevalence and severity of FI decreased over time. At both visits $37.4 \%$ of the households were classified as FS, and at both visits $29.8 \%$ experienced FI; $24.5 \%$ changed from FI to FS, and only $8.3 \%$ began the study as FS and became FI at follow-up (Fig. 2). The majority of households that began the study as FI improved at least one FI security level, and $81.9 \%$ of those classified as FS at baseline remained in this same condition at follow-up (Fig. 2). The proportion of households that changed to the FS level was greater among households that began the study with mild FI (61.0\%).

\section{Housebold income, conditional casb transfer and food insecurity}

Figure 3 shows the predicted probabilities for FI at baseline and follow-up by predictor variable. In both study time points, the probability of FI decreased as per capita household income increased. Regardless of income there was a lower FI at follow-up than baseline, this difference was between 10 and $20 \%$ among households with a per capita 
Table 1 Characteristics of the sample of households by food security (FS) and food insecurity (FI) levels at baseline; Cuité, Paraíba, Brazil, 2011

\begin{tabular}{|c|c|c|c|c|c|c|c|c|}
\hline \multirow[b]{3}{*}{ Baseline characteristics ( $n 358)$} & \multicolumn{8}{|c|}{ Food (in)security baseline (2011) } \\
\hline & \multicolumn{2}{|c|}{ FS $(n 159)$} & \multicolumn{2}{|c|}{ Mild FI $(n 111)$} & \multicolumn{2}{|c|}{ Moderate FI $(n 46)$} & \multicolumn{2}{|c|}{ Severe FI ( $n 42)$} \\
\hline & $\%$ or Mean & SD & $\%$ or Mean & SD & $\%$ or Mean & SD & $\%$ or Mean & SD \\
\hline \multicolumn{9}{|l|}{ Minimum wage multiples per capita ${ }^{\star * \star}, \dagger$} \\
\hline Up to $1 / 4$ minimum wage & $21 \cdot 4$ & - & $46 \cdot 9$ & - & $67 \cdot 4$ & - & 71.4 & - \\
\hline Above $1 / 4$ to $1 / 2$ minimum wage & 23.9 & - & 23.4 & - & $19 \cdot 6$ & - & 21.4 & - \\
\hline Above $1 / 2$ to 1 minimum wage & $29 \cdot 6$ & - & $24 \cdot 3$ & - & $13 \cdot 0$ & - & 4.8 & - \\
\hline Above 1 minimum wage & $25 \cdot 2$ & - & 5.4 & - & - & - & $2 \cdot 4$ & - \\
\hline Household income (\$US) & 899.2 & $1135 \cdot 2$ & 467.9 & $471 \cdot 1$ & 249.5 & 271.5 & 195.9 & 234.7 \\
\hline Participants of PBF ${ }^{\star \star \star}$ & $28 \cdot 3$ & - & 54.9 & - & $69 \cdot 6$ & - & $66 \cdot 7$ & - \\
\hline Total cash transfer amount $(\$ \cup S)^{\star \star \star}$ & 19.7 & $35 \cdot 7$ & $40 \cdot 6$ & $40 \cdot 4$ & $50 \cdot 9$ & $40 \cdot 0$ & $53 \cdot 3$ & $44 \cdot 7$ \\
\hline \multicolumn{9}{|l|}{ Household income dependency on PBF*** } \\
\hline $0 \%$ & $71 \cdot 7$ & - & $45 \cdot 1$ & - & 33.4 & - & $33 \cdot 3$ & - \\
\hline Between 0.1 and $50 \%$ & $23 \cdot 3$ & _- & $50 \cdot 4$ & - & 39.2 & - & $38 \cdot 1$ & - \\
\hline More than $50 \%$ & $5 \cdot 0$ & - & 4.5 & - & $30 \cdot 4$ & - & $28 \cdot 6$ & - \\
\hline Urban region ${ }^{\star \star \star}$ & $81 \cdot 8$ & - & $62 \cdot 2$ & - & $52 \cdot 2$ & - & $50 \cdot 0$ & - \\
\hline Own house $e^{\star \star \star}$ & 70.5 & - & $59 \cdot 0$ & - & $48 \cdot 8$ & - & $26 \cdot 5$ & - \\
\hline Above four household members ${ }^{*}$ & $18 \cdot 9$ & - & $26 \cdot 1$ & - & $37 \cdot 0$ & - & $26 \cdot 1$ & - \\
\hline No children under 18 years in household* & 45.9 & - & $33 \cdot 3$ & - & $26 \cdot 1$ & - & $35 \cdot 7$ & - \\
\hline No workers in household & $30 \cdot 8$ & - & $25 \cdot 2$ & - & $26 \cdot 1$ & - & 35.7 & - \\
\hline No retirees in household ${ }^{* \star *}$ & $55 \cdot 4$ & - & $73 \cdot 6$ & - & $78 \cdot 3$ & - & 87.8 & - \\
\hline No member with high education in household ${ }^{\star \star *}$ & $51 \cdot 6$ & - & 77.5 & - & $82 \cdot 6$ & - & $88 \cdot 1$ & - \\
\hline Food production for self-consumption ${ }^{\star *}$ & $39 \cdot 6$ & - & $54 \cdot 1$ & - & $60 \cdot 9$ & - & 59.5 & - \\
\hline Beneficiary of emergency cash benefits* & $12 \cdot 8$ & - & 14.0 & - & $23 \cdot 8$ & - & $32 \cdot 3$ & - \\
\hline Beneficiary of food assistance programmes & 4.7 & - & $7 \cdot 0$ & - & 11.6 & - & 14.7 & - \\
\hline
\end{tabular}

PBF, Bolsa Família (cash transfer programme).

$\chi^{2}$ test comparing proportion of food (in)security and test $t$ comparing mean of household income and cash transfer amount: ${ }^{\star} P<0.05,{ }^{\star \star} P<0.01$, ${ }^{\star \star \star} P<0.001$. †Minimum wage in Brazil in 2011: \$US 340.6 (R \$ 545 (Brazilian real)).
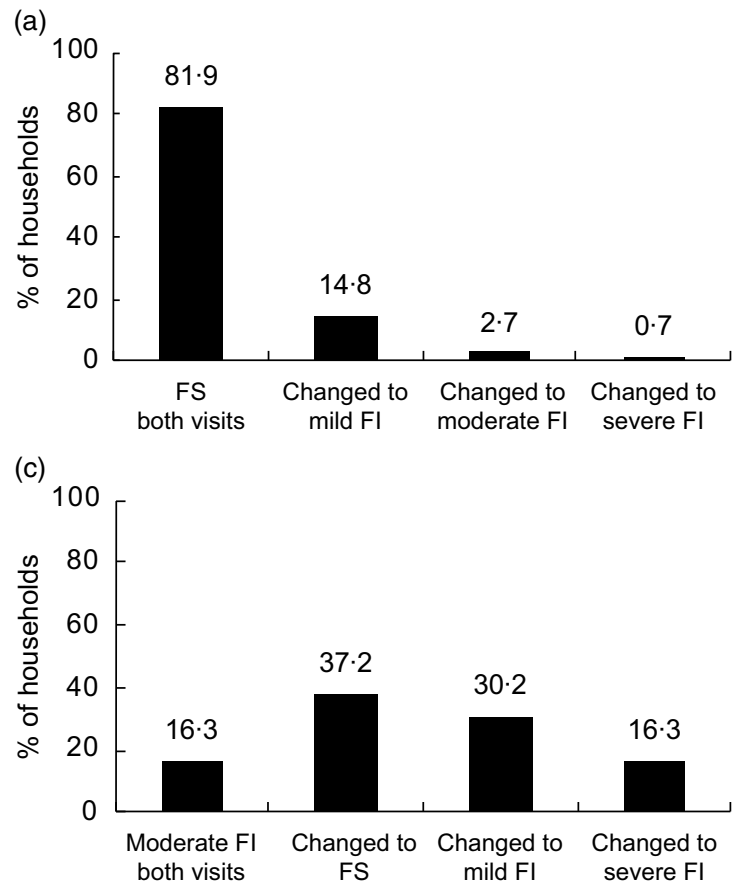

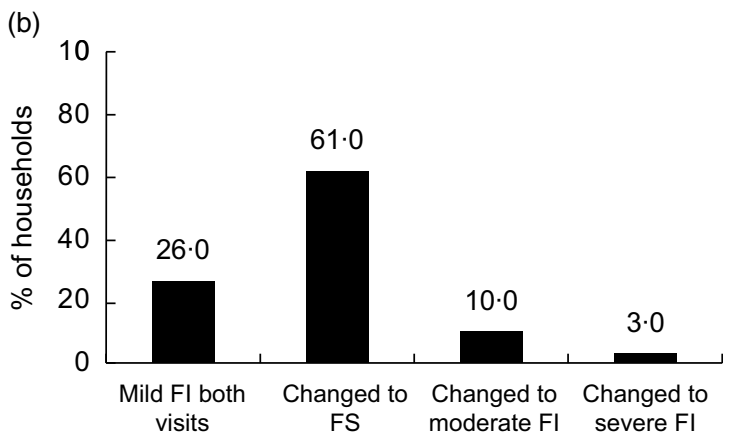

(d)

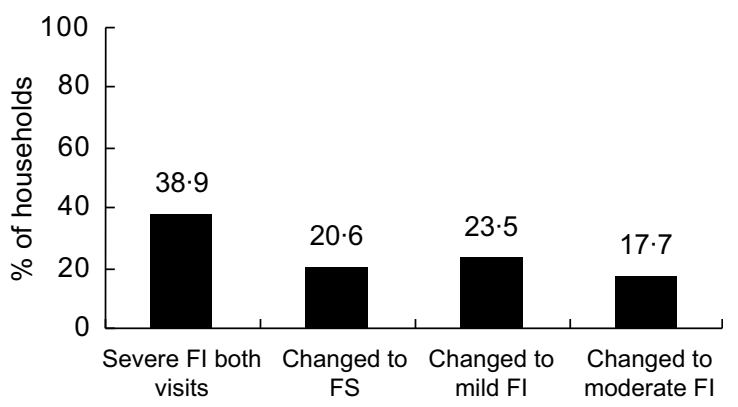

Fig. 2 Dynamics of changes from baseline to follow-up in levels of household food insecurity (FI) among households with (a) food security (FS) at baseline ( $n$ 149), (b) mild FI at baseline ( $n 100)$, (c) moderate FI at baseline $(n 43)$ and (d) severe FI at baseline $(n 34)$; Cuité, Paraíba, Brazil, 2011-2014. Sample size at follow-up, $n 326$ 


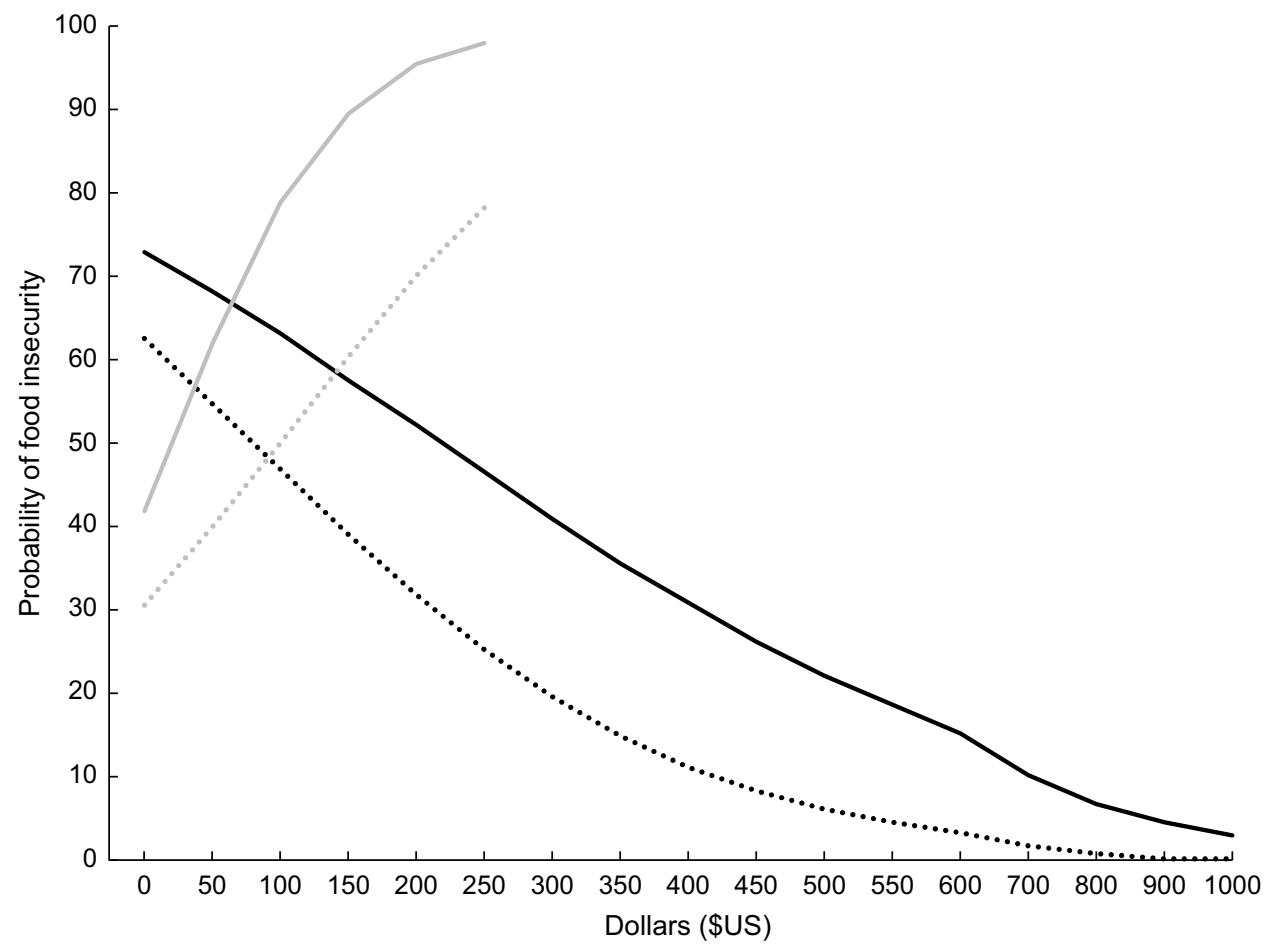

Fig. 3 Probability of food insecurity by household income per capita and total cash transfer amount received at baseline and follow-up ( - , income per capita baseline; ........ income per capita follow-up; - , cash transfer baseline; …...., cash transfer follow-up); Cuité, Paraíba, Brazil, 2011-2014. Logistic regression models adjusted for own home, number of members in family, food production for self-consumption, beneficiary of emergency cash benefits and beneficiary of food assistance programmes at baseline and follow-up. Model for family income per capita follow-up includes family income at baseline; model for cash transfer follow-up includes family income at baseline

Table 2 Dynamics of change in household income and cash transfer amount by change in food security (FS) and insecurity (FI) from baseline to follow-up; Cuité, Paraíba, Brazil, 2011-2014

\begin{tabular}{|c|c|c|c|c|}
\hline \multirow[b]{3}{*}{ Change in characteristic ( $n 326)$} & \multicolumn{4}{|c|}{ Change in food (in)security from baseline to follow-up } \\
\hline & $\begin{array}{l}\text { FS at both visits } \\
(n 122)\end{array}$ & $\begin{array}{l}\mathrm{FI} \text { at both visits } \\
(n 97)\end{array}$ & $\begin{array}{l}\text { Changed to FS } \\
(n 80)\end{array}$ & $\begin{array}{l}\text { Changed to } \mathrm{FI} \\
(\text { (n27) }\end{array}$ \\
\hline & $\%$ & $\%$ & $\%$ & $\%$ \\
\hline \multicolumn{5}{|l|}{ Total household income ${ }^{\star \star \star}$} \\
\hline $\begin{array}{l}\text { Increased by more than } 1 / 2 \text { minimum wage } \dagger \\
\text { from baseline }\end{array}$ & $54 \cdot 9$ & $28 \cdot 8$ & $55 \cdot 0$ & $22 \cdot 2$ \\
\hline $\begin{array}{l}\text { Increased by up to } 1 / 2 \text { minimum wage from } \\
\text { baseline }\end{array}$ & $29 \cdot 5$ & $38 \cdot 1$ & $25 \cdot 0$ & $48 \cdot 2$ \\
\hline Same or less at endline than baseline & $15 \cdot 6$ & 33.0 & 20 & $29 \cdot 6$ \\
\hline \multicolumn{5}{|l|}{ Total cash transfer amount ${ }^{\star \star *}$} \\
\hline Non-beneficiary at both visits & $68 \cdot 0$ & $14 \cdot 4$ & $48 \cdot 7$ & $48 \cdot 1$ \\
\hline Same or more cash at endline than baseline & $24 \cdot 6$ & $69 \cdot 1$ & $36 \cdot 3$ & $48 \cdot 2$ \\
\hline Lesser cash at endline than baseline & $7 \cdot 4$ & $16 \cdot 5$ & $15 \cdot 0$ & $3 \cdot 7$ \\
\hline \multicolumn{5}{|l|}{ Household income dependency on $\mathrm{PBF}^{\star \star \star}$} \\
\hline Non-dependent at both times & $67 \cdot 2$ & $14 \cdot 4$ & $48 \cdot 7$ & $48 \cdot 2$ \\
\hline Same or more at endline than baseline & $13 \cdot 1$ & 47.4 & $15 \cdot 0$ & $25 \cdot 9$ \\
\hline Less at endline than baseline & $19 \cdot 7$ & $38 \cdot 1$ & $36 \cdot 2$ & $25 \cdot 9$ \\
\hline
\end{tabular}

PBF, Bolsa Família (cash transfer programme).

$\chi^{2}$ test comparing proportion of food (in)security: ${ }^{\star * *} P<0.001$.

†Minimum wage in Brazil in 2014: \$US 329.1 (R 724 (Brazilian real)).

income of less than \$US 600. The income level at which half of the households were FI was substantially lower at follow-up compared with baseline, \$US $100 v$. \$US 250, respectively.
The change in FI status between follow-up and baseline was associated with total household income (Table 2). Among those who switched from FI to FS, $80 \%$ had a higher total income at follow-up compared with baseline. 
Table 3 Multivariate regression proposal models $\dagger$ of change in household food security (FS) and food insecurity (FI) over time considering the change in total household income and conditional cash transfer received; Cuité, Paraíba, Brazil, 2011-2014

\begin{tabular}{|c|c|c|c|c|}
\hline \multirow[b]{2}{*}{ Proposal model } & \multicolumn{2}{|c|}{ Changed to FS $(n 80)$} & \multicolumn{2}{|c|}{$\mathrm{FI}$ at both visits $(n 97)$} \\
\hline & OR & $95 \% \mathrm{Cl}$ & OR & $95 \% \mathrm{Cl}$ \\
\hline \multicolumn{5}{|l|}{ Change in total household income and adjusted variables $\ddagger$} \\
\hline \multicolumn{5}{|l|}{ Total household income } \\
\hline Increased by more than $1 / 2$ minimum wage $\S$ from baseline & 1.00 & Ref. & 1.00 & \multirow{3}{*}{$\begin{array}{c}\text { Ref. } \\
0.80,3.53 \\
\mathbf{1 . 9 2}, \mathbf{1 3 . 2 8}\end{array}$} \\
\hline Increased by up to $1 / 2$ minimum wage from baseline & 0.67 & $0.33,1.35$ & 1.69 & \\
\hline Same or less at endline than baseline & 1.57 & $0.65,3.81$ & 5.04 & \\
\hline \multicolumn{5}{|l|}{ Change in total cash transfer amount and adjusted variables $\|$} \\
\hline \multicolumn{5}{|l|}{ Total cash transfer amount } \\
\hline Non-beneficiary at both visits & 1.00 & Ref. & 1.00 & \multirow{3}{*}{$\begin{array}{c}\text { Ref. } \\
1.66,10.58 \\
1.40,16.22\end{array}$} \\
\hline Same or more cash at endline than baseline & 0.71 & $0.26,1.94$ & 4.20 & \\
\hline Lesser cash at endline than baseline & 0.93 & $0.26,3.32$ & 4.77 & \\
\hline \multicolumn{5}{|c|}{ Change in total household income, change in cash transfer amount and adjusted variables } \\
\hline Total household income & & & & \\
\hline Increased by more than $1 / 2$ minimum wage from baseline & 1.00 & Ref. & 1.00 & \multirow{3}{*}{$\begin{array}{c}\text { Ref. } \\
0.98,4.66 \\
\mathbf{2 . 2 0}, \mathbf{1 7 . 2 8}\end{array}$} \\
\hline Increased by up to $1 / 2$ minimum wage from baseline & 0.70 & $0.34,1.45$ & $2 \cdot 14$ & \\
\hline Same or less at endline than baseline & $1 \cdot 70$ & $0.67,4.31$ & $6 \cdot 16$ & \\
\hline \multicolumn{5}{|l|}{ Total cash transfer amount } \\
\hline Non-beneficiary at both visits & 1.00 & Ref. & 1.00 & \multirow{3}{*}{$\begin{array}{c}\text { Ref. } \\
0.60,6.45 \\
\mathbf{1 . 4 2}, \mathbf{1 8 . 6 1}\end{array}$} \\
\hline Same or more cash at endline than baseline & 0.46 & $0.16,1.38$ & 1.96 & \\
\hline Lesser cash at endline than baseline & 0.76 & $0.67,4.31$ & 5.14 & \\
\hline \multicolumn{5}{|c|}{ Change in household income dependency on PBF and adjusted variables†† } \\
\hline \multicolumn{5}{|c|}{ Household income dependency on PBF } \\
\hline Non-dependent at both times & 1.00 & Ref. & 1.00 & Ref. \\
\hline Same or more at endline than baseline & 0.76 & $0.30,1.96$ & 3.92 & $1.36,11.25$ \\
\hline Less at endline than baseline & 1.05 & $0 \cdot 40,2 \cdot 79$ & $1 \cdot 23$ & $0.38,3.95$ \\
\hline \multicolumn{5}{|c|}{$\begin{array}{l}\text { Statistically significant associations }(P<0.05) \text { are indicated in bold font. } \\
\text { tAdjusted for number of members in household (follow-up), food production for self-consumption at household (change), beneficiary of emergency cash benefits (follow-up) } \\
\text { and beneficiary of food assistance programmes (follow-up). } \\
\text { flncludes adjusted variables and household income (baseline). } \\
\text { \$Minimum wage in Brazil in 2014: } \$ U S 329 \cdot 1(\mathrm{R} \$ 724 \text { (Brazilian real)). } \\
\text { |lincludes adjusted variables and cash transfer amount (baseline). }\end{array}$} \\
\hline
\end{tabular}

By contrast, $70 \cdot 4 \%$ of those who switched from FS to FI had a higher income at follow-up compared with baseline.

Table 3 shows the multivariate regression models identifying predictors of change in FI status. Households that did not increase or experienced a decrease in their total income between baseline and follow-up had about six times more odds of remaining FI when compared with households who remained FS at both time points.

There was no association between the change in total household income and the switch from FI at baseline to FS at follow-up $(P=0.341$; Table 3$)$. Figure 4 indicates that the change from FI at baseline to FS at follow-up was much less elastic to household income compared with remaining FI or remaining FS at both study time points.

Regarding the cash transfer from PBF, there was a greater predicted probability of FI at baseline than at follow-up for the same total cash transfer amount from PBF (Fig. 3).

Over two-thirds ( $68 \%$ ) of households classified as FS at both visits did not participate in the PBF. By contrast, among those who were FI at both time points only $14.4 \%$ were not enrolled in PBF (Table 2). Among households that participated in the programme, there was a greater proportion of households that received 'same or more cash' at follow-up than baseline. About $47 \%$ of the households that remained FI at both time points experienced an increase in or maintained the same level of household income dependency on the PBF cash transfer. By contrast, households that switched from FI at baseline to FS at follow-up showed a decrease in PBF cash transfer dependence at follow-up (36.2\%; Table 2).

In the multivariate analysis (Table 3 ), the households that experienced a reduction in total cash transfer amount or increased/maintained their income dependency on PBF had 5.1 and 3.9 times higher odds of experiencing FI, respectively.

Based on the PAR analysis derived from the third multivariate model in Table 3, if PBF had not been in place, then about $10 \%$ of the households that switched from FI to FS during the study would have remained FI instead. However, consistent with the household income findings, the change in the total cash transfer amount between baseline and follow-up was not associated with the likelihood of changing from FI to FS across time (Table 3). 
Family income, cash transfer, food insecurity

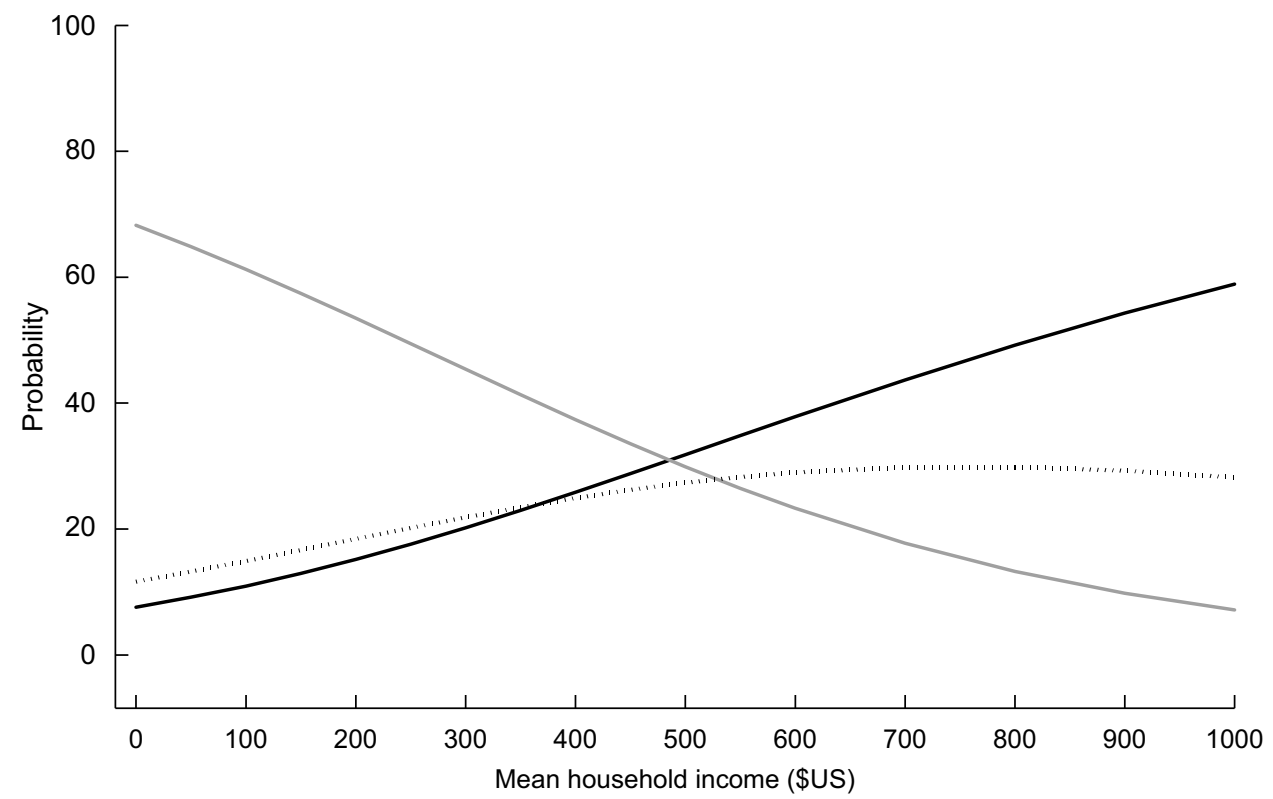

Fig. 4 Probability of changes in food insecurity status ( - , food security at both visits; $\_$, food insecurity at both visits; ......., changed to food security) by mean household income between baseline and follow-up; Cuité, Paraíba, Brazil, 2011-2014. Multinomial logistic regression model adjusted for family income (baseline), number of members in family (follow-up), food production for self-consumption (change), beneficiary of emergency cash benefits (follow-up) and beneficiary of food assistance programmes (follow-up)

\section{Discussion}

The first objective of the present study was to examine if there was a change in household FI between baseline and follow-up 3 years later. Our findings documented a substantial decrease in the prevalence $(-17.5 \%)$ and severity of FI across time, consistent with other national studies that previously documented decreases in the prevalence of FI in Brazil between 2004 and 2013 ${ }^{(8,32)}$. This is a relevant finding because that decade was when a public intersectoral anti-hunger and poverty priority agenda was implemented. This agenda included income redistribution, improvement of rural infrastructure, domestic markets strengthening, minimum wage improvements and addressing unemployment ${ }^{(38)}$. Therefore, the reduction in household FI in our study is likely to be explained, at least in part, by the implementation of public policies that effectively addressed social inequities during the study $\operatorname{period}^{(39)}$

Despite the FI reductions observed in our study, at follow-up the FI rate $(38.1 \%)$ was higher than the average for Brazil $(22.9 \%)^{(32)}$, confirming the high vulnerability for FI in the region and municipality where our study was conducted. Indeed, the Northeast region has the highest prevalence of FI in Brazil reflecting the high level of the well-documented socio-economic and FI inequalities across regions in Brazil. The lowest development of this region is concentrated in the semi-arid area where the study's municipality is located, which corresponds to $20 \%$ of the country's territory. Historically, the north-eastern semi-arid region has faced problems related to persistent drought, poverty and low infrastructure to enable food production ${ }^{(40)}$. In 2012, the region faced the worst drought in the last 50 years $^{(41)}$. These conditions posed great challenges for the design and implementation of public policies to overcome FI, especially in small cities whose economic activity is mainly agriculture $^{(42)}$, as in the case of the study's municipality.

Even in this adverse context, over a 3-year period, about $25 \%$ of households overcame FI at follow-up compared with baseline. Consistent with our study, the only longitudinal study previously conducted in Brazil addressing changes in FI reported a significant decrease in the prevalence of moderate/severe FI between 2005 and $2011(10 \cdot 3 \%)^{(12)}$.

In Canada, different surveys did not point to significant changes in the prevalence of FI across time: (i) in a low-income population in Toronto (68.3\%; 2005$2006)^{(13)}$; (ii) among families with children in Quebec $(9 \cdot 2-7 \cdot 1 \% ; 2002-2008)^{(43)}$; and (iii) in the provinces of Newfoundland and Labrador (15.7\%; 2007-2012) ${ }^{(19)}$. In Uganda researchers reported seasonal variation of severe FI rate in six follow-up waves between 2013 and $2014(79-92 \%)^{(15)}$; and in Kenya, severe FI changed from $48 \%$ in $2007-2009$ and $36 \%$ in 2010 to $39 \%$ in $2012^{(44)}$. Although these countries are not directly comparable to Brazil, it is important to highlight how difficult it is to reduce FI across time and across countries with very different levels of economic development. Thus, the strong magnitude of the shift from FI to FS in a short period of time (i.e. 3 years) observed in our study stands out as a key finding. According to Tarasuk ${ }^{(14)}$, household 
FI is an indication of material and economic conditions; that is, when there is FI, it is assumed that other basic necessities have not been reached. Accordingly, the observed changes may also represent an improvement in the living conditions of families over the years as documented in the poverty and FI literature from Brazil ${ }^{(45,46)}$.

The second objective of the present study was to determine if household income and cash transfers were independently related to the observed changes in FI status across time. The results of multivariate analysis showed that the decrease in household income and cash transfer from PBF from baseline increased the household's odds of remaining FI at both time points, characterizing both sources of income as determinants of FI. Specifically, these findings suggest that the absence or restraint of government investment in cash transfer programmes is a direct determinant of the persistence of FI among vulnerable families.

On the other hand, the increase in household income across time was not significantly associated with the likelihood of overcoming FI, even after taking account of the $30 \%$ increase in minimum wage that occurred in Brazil between 2011 and 2014. A law issued in 2011 established norms for increasing the minimum wage based on the gross domestic product and inflation in the previous years. However, the inflation rate was high during the period of the study (2011: 6.5\%; 2012: 5.8\%, 2013: 5.9\%, 2014: $6 \cdot 4 \%)$ and tended to fluctuate above the minimum wage percentage increase ${ }^{(47,48)}$.

Furthermore, in the context where the study took place characterized by a population with low levels of education, temporary/informal work and strongly engaged in agricultural activities ${ }^{(42)}$, it is possible that the minimum wage increases did not reach the population segments that were most vulnerable to $\mathrm{FI}^{(14)}$. Therefore, if a similar study had been conducted with a less vulnerable population, we may have seen greater effects of the minimum wage policy on FI changes.

Consistent with this hypothesis, a study conducted by Loopstra and Tarasuk ${ }^{(13)}$ pointed out that independent of the amount of household income, the type of employment was associated with a reduction in the severity of FI. In addition to guaranteeing a stable income, the authors argue that in the context of Canada access to credit by employees to cover unexpected expenses can impact the family budget to access food in times of crises. Tarasuk ${ }^{(14)}$ and Li et $a l .{ }^{(18)}$ argue that household FI is a function of both the amount and the stability of the family income source, so that families suffer from low access to food not only as a result of low income, but also of having unstable jobs, i.e. any improvement in household FI resulting from increased wages are contingent on how stable the jobs are.

In contrast with household income, our findings suggested that the cash transfer from PBF was associated with switching from FI to FS across time. Although multivariate analysis showed no association between change in the cash transfer amount and change in FI status across time, there was a greater predicted probability of FI at baseline than at follow-up for the same cash transfer amount (a difference of about $30 \%$ ). Furthermore, we estimated based on PAR that if PBF had not been in place, then $10 \%$ of the households that switched from FI to FS during the study would have remained FI instead.

To our knowledge, no other study has estimated the magnitude of the association between PBF's cash transfer and household FI. Cabral et ll $^{(12)}$ did previously suggest that $\mathrm{PBF}$ was associated with reducing moderate/severe FI among families in north-eastern Brazil; however, they did not estimate the effect size. Other studies have evaluated the impact of different cash transfer programmes on lowering the prevalence of household FI. In the USA, surveys indicate that the Supplemental Nutrition Assistance Program (SNAP) reduces FI in families on the programme by about $30 \%{ }^{(49,50)}$; however, another SNAP study did not confirm this finding ${ }^{(51)}$. In Canada, there was a reduction in the chance of moderate and severe FI among the families that received welfare income between 2005 and 2012 ${ }^{(19)}$, but another study also in Canada found no association between cash transfer from social assistance and $\mathrm{FI}^{(13)}$. In sub-Saharan Africa, cash transfer programmes in Zimbabwe and Zambia were associated with reductions in household $\mathrm{FI}^{(52)}$. Hence, it is possible that cash transfer programmes may have stronger impacts at reducing FI in populations where severe poverty is extensive such as in the municipality where our study took place.

The comparison between these studies is limited by the diversity in the design of the cash transfer programmes. $\mathrm{PBF}$ is a conditional cash transfer programme, which includes the monthly receipt of unrestricted cash benefits through electronic cards ${ }^{(53)}$. Unlike PBF, SNAP restricts the use of benefits to the purchase of food; in Canada the receipt of welfare benefits is not linked to conditionalities to beneficiaries; in Africa, the benefits in cash are delivered every 2 months to beneficiaries. Thus, beyond the cash transfer amount, the programme design may potentiate $^{(14,54)}$ or constrain ${ }^{(55)}$ the impact that cash transfers can have on household FI.

Some positive aspects of the PBF may contribute to help families overcome FI. In addition to increasing the family budget, PBF is characterized by: (i) the regularity of the transfer of benefits, providing a degree of income stability for the family, which in turn can facilitate access to credit; (ii) transfer of the direct benefit to the family through an efficient and transparent debit card electronic system; and (iii) access to a public network of a suite of complementary social, agriculture and health protection programmes to support the families in times of need. Further prospective studies are needed to identify potential pathways through which PBF may protect vulnerable families against FI.

The present study evaluated the effect of different sources of income on FI in a region whose challenges to overcoming FI are also related to lack of access to water, 
food production and access to markets. In future research it will be important to extend the FI secular trends analysis to account for other factors such as the improvements in production and availability of foods and the road conditions for transportation of foods and other basic goods in rural regions.

\section{Limitations}

Our findings are robust given that they are based on a strong study design. First, we conducted a longitudinal study with strong internal validity including the comparison of the same families with the same survey instruments across time. Second, we applied multiple regression analyses adjusting for potential confounders thereby reducing the possibility of bias when interpreting findings. Although we cannot draw causal inferences with absolute certainty from our findings, the careful study design and robust statistical analyses give us confidence on interpreting our PAR findings assuming a causal relationship ${ }^{56,57)}$. However, several limitations must also be recognized.

First, a limitation from our study is that it was not possible to examine the association between the cash transfer and changes in different severity levels of FI due to the small sample size. Likewise, sample size limitations did not allow to analyse the results for the groups of families that switched from FS to FI during the study.

Second, there are many methodological challenges to analysing the impact of cash transfer programmes on FI. According to Nord ${ }^{(49)}$, selection bias is inherent in these studies, since families that have greater difficulty with access to food are prioritized in the participation of these programmes. In the present study we did not analyse only beneficiary families, but rather a random sample of families at two time points, which can reduce this type of bias.

Another potential limitation is our analytical choice to grouping families into longitudinal categories of FI change. Because the outcome studied is based on an ordinal variable with four categories, the longitudinal secular analysis led to sixteen possible combinations for modelling outcomes. However, sample size limitations did not allow us to conduct the analysis by level of FI severity. Furthermore, the conceptual framework behind FI experience-based scales such as EBIA does not support modelling FI as a continuous variable ${ }^{(58)}$. Indeed, our FI secular change modelling approach has been previously recommended for prospective studies ${ }^{(59,60)}$. The FI construct measured through experience-based food insecurity scales such as EBIA has been consistently represented through an ordered categorical variable ${ }^{(28)}$. Recently, Reichenheim et $a l .{ }^{(28)}$ confirmed this to be the case for EBIA by applying latent class factor analysis models and confirming the presence of four homogeneous groups with a very high degree of class separation corresponding to different levels of severity of FI.
Therefore, the results from our study are based on a sound conceptual framework and robust statistical analyses that shed new light into the relationship between cash transfer programmes and FI, which currently is a topic of global interest.

\section{Conclusions}

Our findings from Brazil, a country with a strong history of implementation of policies to combat poverty and hunger and poverty, document major improvements in FI between 2011 and 2014 among households located in an area of extreme climatic and social vulnerability. This encouraging finding in one of the poorest municipalities in Brazil is likely the result of the increased investments in addressing the social determinants of health through social protection policies during the time period when the study was conducted.

Our conclusions may be applicable to other populations that face high prevalence of FI and chronic poverty related to insufficient education and engagement with agricultural production, although further research in different contexts is needed to confirm the results of the present study.

Our findings reinforce the evidence that the persistence of FI is strongly determined by the household's income and the lack of access to social protection programmes such as PBF. In our study, overcoming household FI was influenced more by the cash transfer programme than by the increase in household income across time. We hypothesize that this is because PBF not only increases the family budget but also offers access to other benefits on a regular basis as well as a network of support and social protection that could potentiate its protective effects on household FI.

\section{Acknowledgements}

Financial support: The authors thank the Brazilian National Research Council (Conselho Nacional de Pesquisa (CNPq)) and the Ministry of Social Development (MDS) for support in this research. This study was supported by MDS/CNPq in 2011 (grant number 563883/2010-3) and 2014 (grant number 457022/2013-2). MDS and CNPq had no role in the design, analysis or writing of this article. Conflict of interest: None. Authorship: P.A.P. participated in the concept, design of the study and data collection, coordination and supervision of the data collection, and analysing, writing and revising the manuscript. R.P.-E. participated in the manuscript concept, data interpretation and in manuscript revising. R.S.-C. participated in data interpretation and in manuscript revising. Ethics of human subject participation: This study was conducted according to the guidelines laid down in the Declaration of Helsinki and all procedures involving human subjects were approved by the Ethics Committee of the State University of Paraíba (2011; number 
0102.0.133.000-11) and University Hospital Alcides Carneiro (2014; number 30919314.6.0000.5182). Written informed consent was obtained from all participants.

\section{References}

1. Food and Agriculture Organization of the United Nations (2009) Glossary on Right to Food, p. 138. Rome: FAO.

2. Parker ED, Widome R, Nettleton JA et al. (2010) Food security and metabolic syndrome in US adults and adolescents: findings from the National Health and Nutrition Examination Survey, 1999-2006. Ann Epidemiol 20, 364-370.

3. Seligman HK, Laraia BA \& Kushel MB (2010) Food insecurity is associated with chronic disease among low-income NHANES participants. J Nutr 140, 304-310.

4. Muldoon KA, Duff PK, Fielden S et al. (2013) Food insufficiency is associated with psychiatric morbidity in a nationally representative study of mental illness among food insecure Canadians. Soc Psychiatry Psychiatr Epidemiol 48, 795-803.

5. Leung CW, Epel ES, Willett WC et al. (2015) Household food insecurity is positively associated with depression among low-income supplemental nutrition assistance program participants and income-eligible nonparticipants. J Nutr 145, 622-627.

6. Roncarolo F \& Potvin L (2016) Food insecurity as a symptom of a social disease: analyzing a social problem from a medical perspective. Can Fam Physician 62, 291-292.

7. Loopstra R, Reeves A \& Stuckler D (2015) Rising food insecurity in Europe. Lancet 385, 2041.

8. Gubert MB, Santos SMC, Santos LMP et al. (2017) A municipal-level analysis of secular trends in severe food insecurity in Brazil between 2004 and 2013. Glob Food Sec 14, 61-67.

9. Food and Agriculture Organization of the United Nations (2015) Panorama de la Inseguridad Alimentaria en América Latina y el Caribe. La Región Alcanza las Metas Internacionales del Hambre, p. 78. Santiago: FAO.

10. Food and Agriculture Organization of the United Nations, International Fund for Agricultural Development, UNICEF et al. (2017) The State of Food Security and Nutrition in the World 2017. Building Resilience for Peace and Food Security. Rome: FAO.

11. Food and Agriculture Organization of the United Nations (2017) Global Strategic Framework for Food Security and Nutrition (GSF) 2017 Edition. Rome: Committee on World Food Security, FAO.

12. Cabral CS, Lopes AG, Lopes JM et al. (2014) Food security, income, and the Bolsa Familia program: a cohort study of municipalities in Paraiba State, Brazil, 2005-2011. Cad Saude Publica 30, 393-402.

13. Loopstra R \& Tarasuk V (2013) Severity of household food insecurity is sensitive to change in household income and employment status among low-income families. $J$ Nutr 143, 1316-1323.

14. Tarasuk V (2017) Implications of a Basic Income Guarantee for Household Food Insecurity. Thunder Bay, ON: Northern Policy Institute.

15. Patterson K, Berrang-Ford L, Lwasa S et al. (2017) Seasonal variation of food security among the Batwa of Kanungu, Uganda. Public Health Nutr 20, 1-11.

16. Mohammadi-Nasrabadi F (2016) Impact of cash transfer on food security: a review. Nutr Food Sci Res 3, 3-10.

17. Loopstra R, Reeves A, McKee M et al. (2016) Food insecurity and social protection in Europe: quasi-natural experiment of Europe's great recessions 2004-2012. Prev Med 89, 44-50.

18. Li N, Dachner N \& Tarasuk V (2016) The impact of changes in social policies on household food insecurity in British Columbia, 2005-2012. Prev Med 93, 151-158.
19. Loopstra R, Dachner N \& Tarasuk V (2015) An exploration of the unprecedented decline in the prevalence of household food insecurity in Newfoundland and Labrador, 20072012. Can Public Policy 41, 191-206.

20. Burchi F, Scarlato M \& D'Agostino G (2016) Addressing Food Insecurity in Sub-Saharan Africa: The Role of Cash Transfer. Discussion Paper. Bonn: German Development Institute.

21. Marques ES, Reichenheim ME, de Moraes CL et al. (2015) Household food insecurity: a systematic review of the measuring instruments used in epidemiological studies. Public Health Nutr 18, 877-892.

22. Pérez-Escamilla R \& Segall-Corrêa AM (2008) Food insecurity measurement and indicators. Rev Nutr 21, Suppl., 15S-26S.

23. United Nations Development Programme (2010) Human Development Atlas in Brazil. http://atlasbrasil.org.br/2013/ en/ (accessed August 2017).

24. Vianna RPdT \& Segall-Corrêa AM (2008) Insegurança alimentar das famílias residentes em municípios do interior do estado da Paraíba, Brasil. Rev Nutr 21, Suppl., 111S-122S.

25. Instituto Brasileiro de Geografia e Estatística (2010) Censo Demográfico 2010. Rio de Janeiro, RJ: IBGE.

26. Perez-Escamilla R, Segall-Correa AM, Kurdian Maranha L et al. (2004) An adapted version of the US Department of Agriculture food insecurity module is a valid tool for assessing household food insecurity in Campinas, Brazil. J Nutr 134, 1923-1928.

27. Segall-Corrêa AM, Marin-León L, Melgar-Quiñonez H et al. (2014) Refinement of the Brazilian household food insecurity measurement scale: recommendation for a 14-item EBIA. Rev Nutr 27, 241-251.

28. Reichenheim ME, Interlenghi GS, Moraes CL et al. (2016) A model-based approach to identify classes and respective cutoffs of the Brazilian household food insecurity measurement scale. J Nutr 146, 1356-1364.

29. Segall-Correa AM, Perez-Escamilla R, Marin-Leon L et al. (2009) Evaluation of household food insecurity in Brazil: validity assessment in diverse sociocultural settings. In Initiativa América Latina y Caribe sin Hambre, pp. 80-101 [FAO, editor]. Santiago: Oficina Regional FAO-Chile.

30. Kepple AW \& Segall-Corrêa AM (2011) Conceptualizing and measuring food and nutrition security. Cienc Saude Colet 16, 187-199.

31. Brasil (2010) Nota Técnica 128: Relatório da Oficina Ténica para Análise da Escala de Medida Domiciliar da Insegurança Alimentar. Brasília, DF: Ministério de Desenvolvimento Social e Combate à Fome, Secretaria de Avaliação e Gestão da Informação.

32. Instituto Brasileiro de Geografia e Estatística (2014) Pesquisa Nacional por Amostra de Domicílios: Segurança Alimentar 2013. Rio de Janeiro, RJ: IGBE.

33. Soares SSD (2012) Bolsa Família, Its Design, Its Impacts and Possibilities for the Future. Brasilia, DF: International Policy Centre for Inclusive Growth.

34. Falcão T \& Costa PV (2015) Brazil Without Extreme Poverty: New Perspectives for Brazilian Social Protection. One Pager no. 301. Brasília, DF: International Policy Centre for Inclusive Growth.

35. Newson RB (2013) Attributable and unattributable risks and fractions and other scenario comparisons. Stata J 13, 672-698.

36. Hair JF (2009) Análise Multivariada de Dados, 6th ed. Porto Alegre, RS: Bookman.

37. Stata (2011) Data Analysis and Statistical Software, $13.0 \mathrm{ed}$. College Station, TX: Stata Corporation.

38. Paes-Sousa R \& Vaitsman J (2014) The zero hunger and Brazil without extreme poverty programs: a step forward in Brazilian social protection policy. Cien Saude Colet 19, 4351-4360.

39. Food and Agriculture Organization of the United Nations, International Fund for Agricultural Development \& World 
Food Programme (2014) The State of Food Insecurity in the World 2015. Strengthening the Enabling Environment for Food Security and Nutrition. Rome: FAO.

40. Pérez-Marin AM, Rogé P, Altieri MA et al. (2017) Agroecological and social transformations for coexistence with semi-aridity in Brazil. Sustainability 9, 900.

41. World Meteorological Organization (2014) WMO Statement on the Status of the Global Climate in 2013. Geneva: WMO.

42. Instituto Brasileiro de Geografia e Estatística (2011) Indicadores Sociais Municipais uma Análise dos Resultados do Universo do Censo Demográfico 2010. Rio de Janeiro, RJ: IBGE.

43. Carter MA, Dubois L, Tremblay MS et al. (2012) Local social environmental factors are associated with household food insecurity in a longitudinal study of children. BMC Public Health 12, 1038.

44. Mutisya M, Ngware MW, Kabiru CW et al. (2016) The effect of education on household food security in two informal urban settlements in Kenya: a longitudinal analysis. Food Sec 8 , 743-756.

45. Santos TGd, Silveira JACd, Longo-Silva G et al. (2018) Tendência e fatores associados à insegurança alimentar no Brasil: Pesquisa Nacional por Amostra de Domicílios 2004, 2009 e 2013. Cad Saude Publica 34, e00066917

46. Kepple AW (2014) O Estado da Segurança Alimentar e Nutricional no Brasil: Um Retrado Multimensional. Brasília, DF: FAO.

47. Weisbrot M, Johnston J \& Lefebvre S (2014) The Brazilian Economy in Transition: Macroeconomic Policy, Labor and Inequality. Washington, DC: Center for Economic and Policy Research.

48. Brazil (2011) Law n $n^{\circ} 12.382$ of 2011, February 25. Provides for value the minimum wage in 2011 and its long-term valuation policy; disciplines the fiscal representation for criminal purposes in cases where the tax credit has been parceled out; amends Law $n^{\circ}$ 9,430 of December 27, 1996; and repeals Law $n^{\circ}$ 12,255, of June 15, 2010. Brasilia, DF: Diário Oficial da União.

49. Nord M (2012) How much does the Supplemental Nutrition Assistance Program alleviate food insecurity? Evidence from recent programme leavers. Public Health Nutr 15, 811-817.
50. Mabli J \& Ohls J (2015) Supplemental Nutrition Assistance Program participation is associated with an increase in household food security in a national evaluation. $J$ Nutr 145, 344-351.

51. Leung CW, Cluggish S, Villamor E et al. (2014) Few changes in food security and dietary intake from short-term participation in the Supplemental Nutrition Assistance Program among low-income Massachusetts adults. J Nutr Educ Behav 46, 68-74.

52. Hjlem L (2016) The Impact of Cash Transfers on Food Security. Innocenti Research Briefs. Florence: UNICEF Office of Research - Innocenti.

53. Campello T \& Neri M (2014) Bolsa Família Programa: A Decade of Social Inclusion in Brazil - Executive Summary. Brasíli, DF: Ipea.

54. Power EM, Little MH \& Collins PA (2015) Should Canadian health promoters support a food stamp-style program to address food insecurity? Health Promot Int 30, 184-193.

55. Tiwari S, Daidone S, Ruvalcaba MA et al. (2016) Impact of cash transfer programs on food security and nutrition in sub-Saharan Africa: a cross-country analysis. Glob Food Sec 11, 72-83.

56. Morgenstern H \& Bursic ES (1982) A method for using epidemiologic data to estimate the potential impact of an intervention on the health status of a target population. J Community Health 7, 292-309.

57. Perez L \& Künzli N (2009) From measures of effects to measures of potential impact. Int J Public Health $\mathbf{5 4}$ $45-48$.

58. Nord M (2012) Assessing Potential Technical Enhancements to the US Household Food Security Measures. Technical Bulletin. Washington, DC: US Department of Agriculture, Economic Research Service.

59. Garcia J, Hromi-Fiedler A, Mazur RE et al. (2013) Persistent household food insecurity, HIV, and maternal stress in peri-urban Ghana. BMC Public Health 13, 215.

60. Frongillo E \& Nanama S (2006) Development and validation of an experience-based measure of household food insecurity within and across seasons in northern Burkina Faso. J Nutr 136, issue 5, 1409S-1419S. 